\title{
Application of Six Sigma in a company Automotive in Morocco
}

\author{
Fatima Ezzahra Achibat ${ }^{1, *}$, Ahmed Lebkiri' ${ }^{1}$, and El Mahjoub Aouane ${ }^{2}$ \\ ${ }^{1}$ Laboratory of Advanced Materials and Process Engineering (LAMPE), Faculty of Sciences, Ibn Tofaïl University, Kenitra, \\ Morocco \\ ${ }^{2}$ Laboratory Agroresource Biotechnology Environment and Quality, Faculty of Sciences, Ibn Tofail University, Kenitra, Morocco
}

\begin{abstract}
Customer satisfaction is the key to success in all organizations and this satisfaction has a correlational relationship with the quality so that is why we notice that during the last ten years, the automotive sector focuses on the quality whose new strategy reinforces to develop quality and anchors Morocco in the global automotive industry. This article describes the use of Six Sigma through the DMAIC method (Define, Measure, Analyze, Improve and Control) during production lines in a wiring company. The objective is to reduce the defect rate to improve the quality of the product. After defining the workplace and measuring the defect rate, a structured analysis was done to find the root causes and then actions were implemented to reduce the defect rate. To this effect, the deployment of this method has reduces the rate of defects. The use of the Six Sigma method plays a key role in improving the quality of the product as well as financial gains for the different companies.
\end{abstract}

Keywords: Quality, Six sigma, DMAIC.

\section{Introduction}

During the last ten years, The Moroccan automotive industry has grown in the production and export of automotive equipment and vehicles[1]. The industry has been resilient in the face of the economic crisis, which has not affected the automobile manufacturing segment, although its effect has been felt on national equipment manufacturers[2]. This automotive sector is one of the areas where efforts have been made to apply Six Sigma as it is a competitive market where high quality and safety standards are required[3].

The Six Sigma approach was adopted in Motorola by Bob Galvin and Bill Smith in the mid-1980s and many companies were the first to use Six Sigma as allied Signal, 3M and GE[4]. The origin of the word Sigma is from the Greek alphabet and from a quality point of view, sigma $(\sigma)$ is used to measure changes in the process[5]. Now, Six Sigma is used in different industries such as automotive, electronics, energy, logistics and other fields of industry and these industries have been successful in their activities in terms of product quality as well as financial gains[6]. A study was made containing the collection of different articles between 2005 and 2019 in the use of Six Sigma on different industries and the result obtained that after the implementation of this methodology, most of the organizations obtained a process improvement, rework, waste, reduction of defects and a considerable improvement on the financial side[7]. Six Sigma is the extension of Total Quality Management (TQM)[8], which aims to improve quality and productivity, reduce defects, minimize costs, save time and improve customer satisfaction[9]. The statistical objectives of Six Sigma are to reduce process variation. Six Sigma has a

\footnotetext{
${ }^{*}$ Corresponding author: Fati.achibat@gmail.com
}

statistical performance objective of operating with only 3.4 defects per million opportunities (DPMO)(Fig.1)[3,10].

\begin{tabular}{|c|c|}
\hline$\sigma$ & PPM \\
\hline 1 & 697,672 \\
\hline 2 & 308,537 \\
\hline 3 & 66,807 \\
\hline 4 & 6,210 \\
\hline 5 & 233 \\
\hline 6 & 3.4 \\
\hline $\begin{array}{c}\text { Process } \\
\text { capability }\end{array}$ & $\begin{array}{c}\text { Defects per } \\
\text { milion } \\
\text { opportunities }\end{array}$ \\
\hline
\end{tabular}

Fig.1. The sigma level and the number of defects per million

The key factor in the success of the Six Sigma method is DMAIC's approach[11]. DMAIC is a tool for continuous improvement and a method for problemsolving and process optimization, it consists of five steps: Define, Measure, Analyze, Improve and Control[12], [13].

The Define phase:

- Define the project framework, describe the process to be studied and determine the scope of work

- Identify the needs and dismantle the problem to be solved. 
- Define customer needs.

The Measure phase:

- Identify the various defects to be treated and follow up to detect major problems.

- Develop a data collection plan

- Follow the identified critical variables.

- Analysis of the measurement system.

The Analysis phase:

- Decompose and analyze the problem to identify root causes using different analysis tools for problem-solving.

- Review and analyze data

The phase Improve:

- Propose an action plan and implement effective and feasible actions to address the problems.

- Experiment, modify and statistically prove that the improvements are effective.
- Build an efficient and effective team

- Create ideas for improvement.

- Implement improvement solutions.

The Control phase:

- The evaluation of the improvement actions implemented. This is the stage of verification of the results of the solutions and their effectiveness.

- Apply the solution and put it under control.

- Establish a standard metric to maintain performance

To better apply the DMAIC approach, it is necessary to use relevant and effective methods and tools to succeed in each step of DMAIC, so this figure (Fig.2) illustrates the tools that can be used in each step of this process.[14]

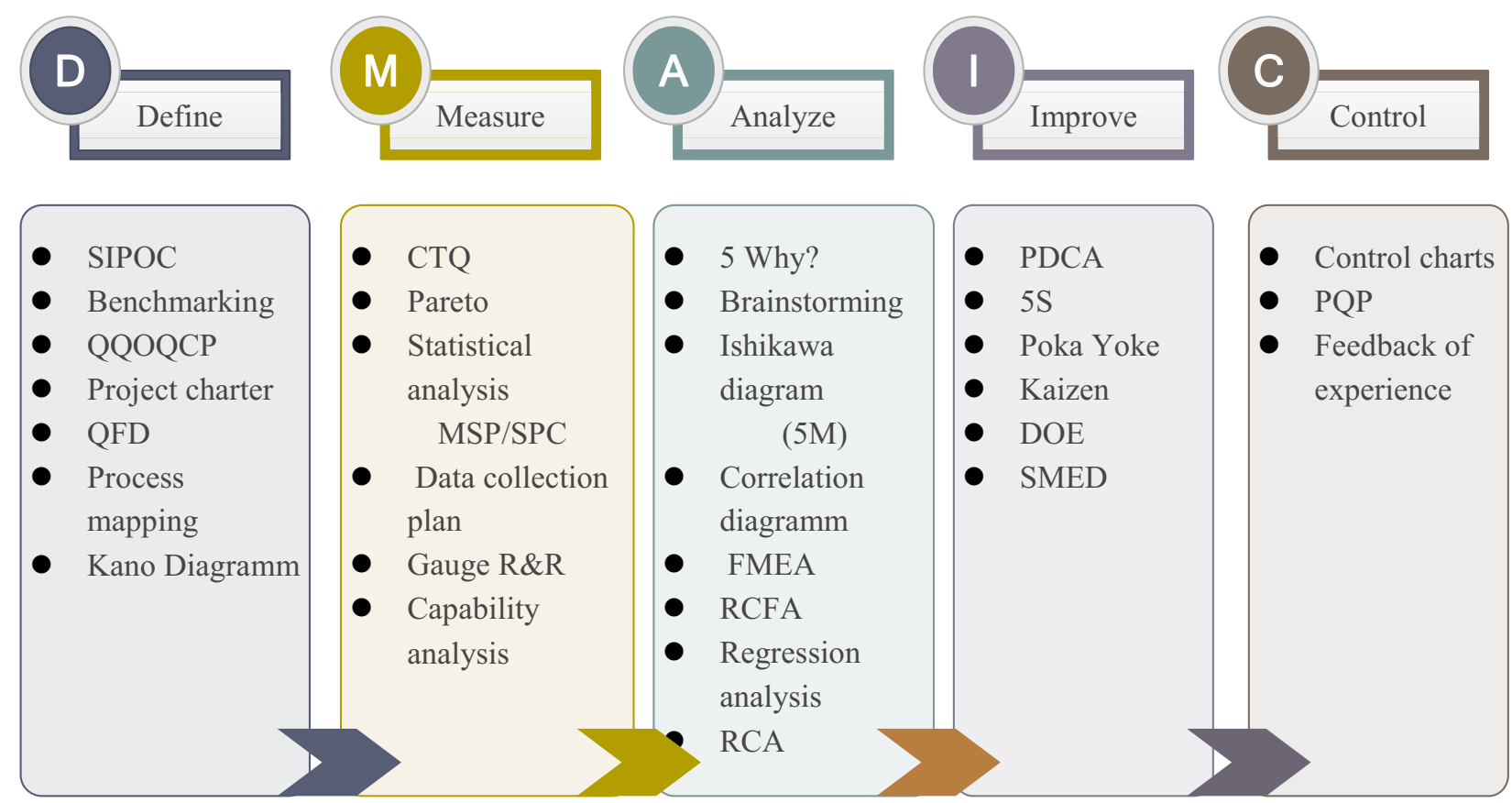

Fig.2. Tools used in the DMAIC approach

\section{Case Study}

A QC (Quality Class) follow-up of the various project was done to identify the critical project, (Target $\mathrm{QC}=0.5$; Threshold=1; QC=0 Very good; QC $=5$ Very bad) then a thorough analysis of the different processes contributing to the manufacturing of the cables using different analysis tools to identify the major defects. The study of the data that was collected allowed me to identify the root causes of each type of defect, and then actions are put in place for each problem. This study was done using Minitab software, which is an important tool for statistical analysis. The main goal of this project is to minimize the defect rate related to the quality department.

\subsection{Define}

Define is the first step in the DMAIC approach, it consists of defining the project framework, describing the process and defining the work environment. To do this, I used the SIPOC method (Supplier, Inputs, Process, Outputs and Customer) which is a process map that describes the flow from supplier input to customer output. The process consists of three areas: Cutting, Preassembly and Assembly. The interest of SIPOC is to visualize the different elements that enter the process as well as the QQOQCP method (What? Who? Where? When? How? Why?) which is used to identify the workplace which is the assembly area.

I used the Pareto chart of the Quality Classes of the different projects for January, the project FIAT is the most critical ( $Q C=2.30)$. Once the projects to be studied have been chosen, the critical families and the various defects to be treated must be identified. 


\subsection{Measure}

"We can only improve what we measure," it is within this framework that this step is carried out, the objective of which is to find the current status of Project FIAT. According to the determination of the critical project, it is necessary to identify the families detected as well as the various defects to be treated and follow up to detect major problems.(Fig.3)

The role of the $\mathrm{P}$ and $\mathrm{U}$ chart is to determine the defective elements and the number of defects per unit respectively, so from Fig. 4 we can see that there are several defects detected and by using the Pareto diagram, the major defect is dimensional defect specifically on the long side.

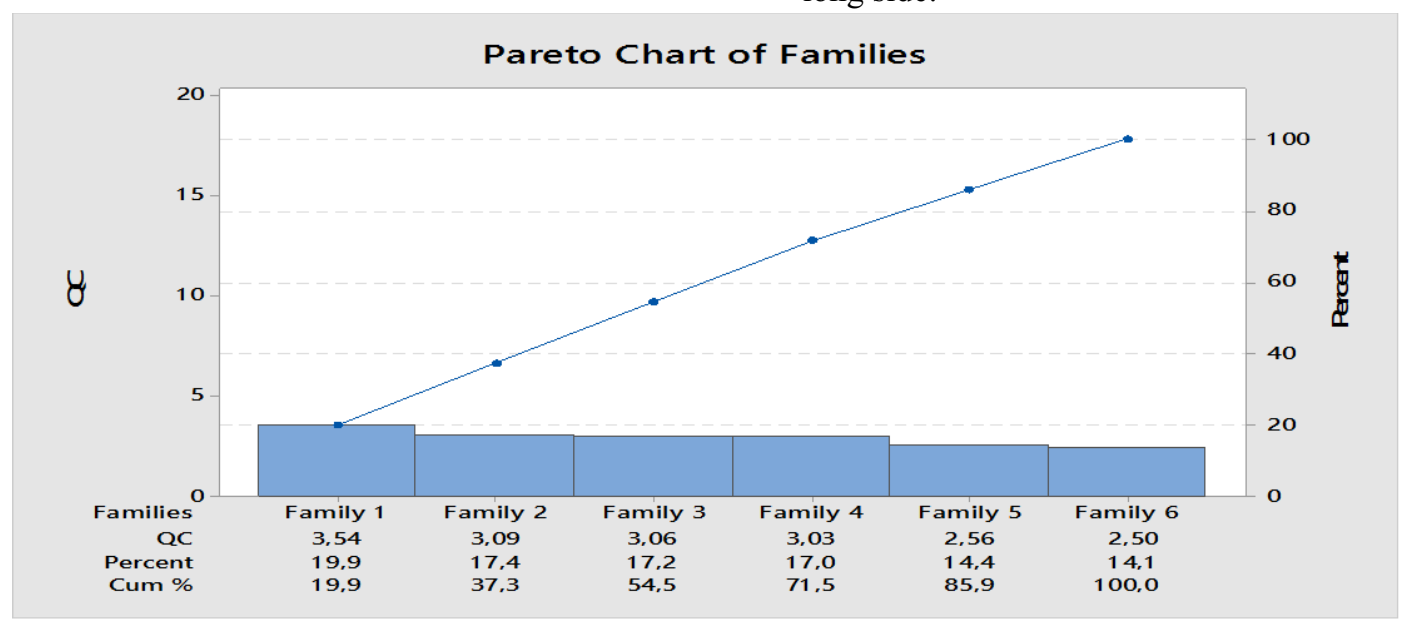

Fig.3. Pareto Diagram of Project 1 Families
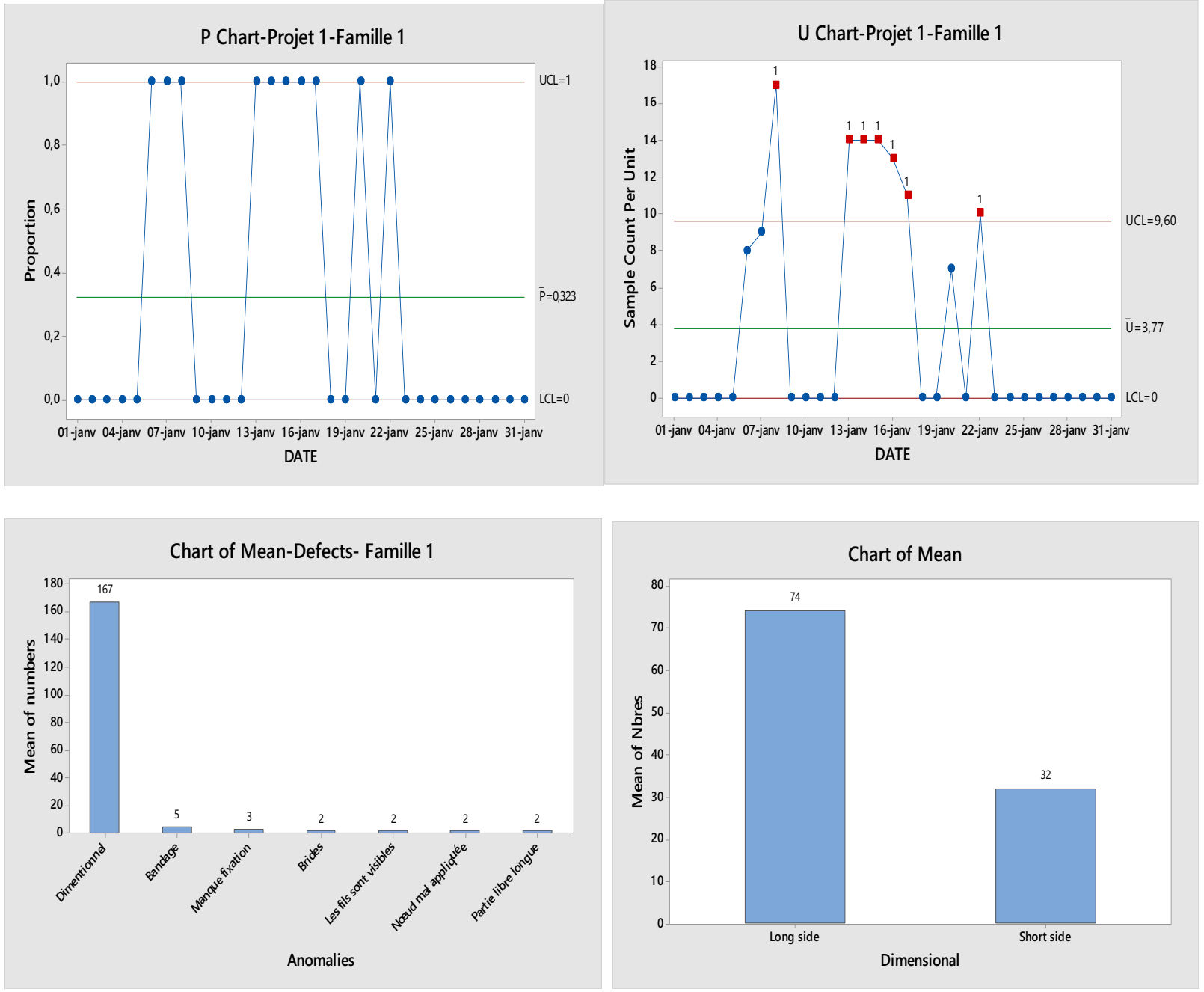

Fig.4. Pareto diagrams of the different problems in family 1 


\subsection{Analyze}

By the DMAIC methodology, the first phases allowed us to define the problem, measure the current state, and have a clear picture of the issues that needed to be addressed. The purpose of the "Analyze" step is to break down and analyze the problem and identify root causes using different analysis tools that are used to solve the problems.

The "Measure" phase has shown that the major problem is a dimensional problem, therefore to analyze and identify the different factors causing this defect, an Ishikawa diagram has been utilized (fig.5).

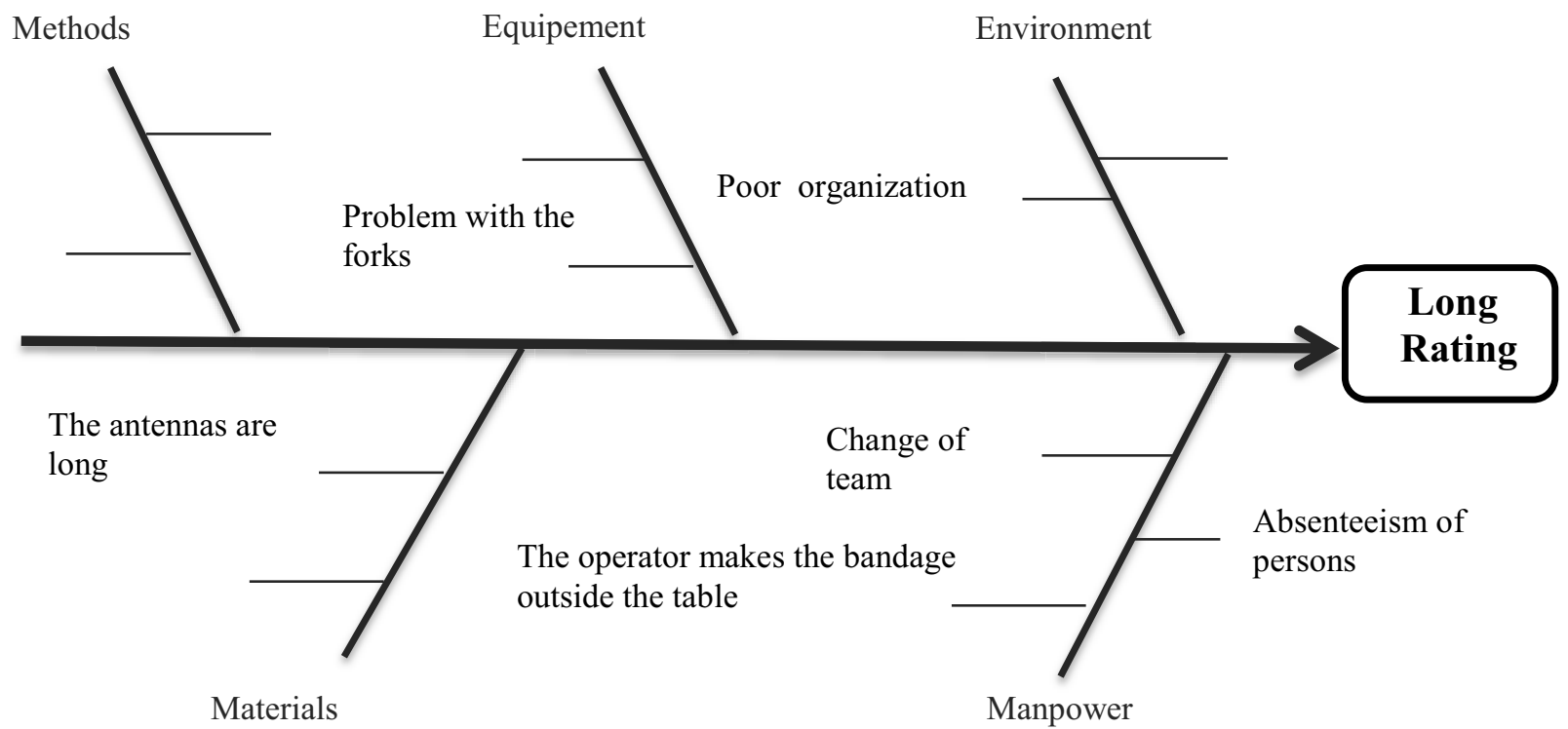

Fig.5.Ishikawa Diagram

\subsection{Improve}

In the light of the analysis carried out in the previous section, we were able to find out the causes of the various quality defects and analyze them. Effective and feasible actions must be taken to remedy these problems. So meetings were made by the person in charge of quality and reliability to validate the implemented actions.

Table 1. The Family Action Plan 1

\begin{tabular}{|c|c|c|c|c|c|}
\hline Project & Family & Problem & Description & Causes & Actions \\
\hline Project 1 & Family 1 & $\begin{array}{l}\text { Long } \\
\text { Side }\end{array}$ & $\begin{array}{l}\text {-Long dimension } \\
\text { between E017 PI } \\
\text { and N } 27 . \\
\text { - Long dimension } \\
\text { between N } 30 \text { and } \\
\text { N } 27 . \\
\text { - Long dimension } \\
\text { between N } 34 \text { and } \\
\text { B } 43 .\end{array}$ & $\begin{array}{l}\text { - People not } \\
\text { specified for } \\
\text { this position. } \\
\text { - The operator } \\
\text { makes the } \\
\text { bandage } \\
\text { outside of the } \\
\text { table. } \\
\text { - Antennas are } \\
\text { long. } \\
\text { - Pressure on } \\
\text { the drills. }\end{array}$ & $\begin{array}{l}\text { - Operator } \\
\text { Awareness. } \\
\text { - To have } \\
\text { qualified people in } \\
\text { this position. } \\
\text { - Contact the } \\
\text { engineering } \\
\text { department and } \\
\text { specify the exact } \\
\text { length of the } \\
\text { Antennas. } \\
\text { - Repair or change } \\
\text { of drills. }\end{array}$ \\
\hline
\end{tabular}




\subsection{Control}

"Control" is the evaluation phase of the improvement actions implemented. The major problem is the staff, so training sessions for the operators have been established by the company, in addition to the repair of the forks by the reliability department, the number of defects is decreasing.

\section{Conclusion}

The company is led to perpetually develop the quality of its products and its performance in general, always aiming at customer satisfaction. In order to maintain its leading position in the market, it must mobilize all stakeholders and players, from simple operators to managers, to integrate into this approach and instill in them the culture of continuous improvement. From this perspective, the use of Six Sigma is very important in different companies because it is used to improve performance that focuses on reducing the number of defects in products, processes and services and this is the case for this case study.

Therefore, this document describes the application of the DMAIC method which is one of the quality improvement methods in the Six Sigma concept in an automotive company. After defining the study area and measuring the rate of defects, a deep and structured analysis was carried out to know the root causes of these defects and then implement relevant actions.

Six Sigma remains a very effective method adopted by many companies to improve their quality and productivity. According to the use of the Six Sigma approach, most companies have been successful in their activities in terms of product quality and on the financial side[7].

To remain competitive in the global market, environmental awareness leads companies to comply with environmental regulations, so it is approved that the Six sigma method brings not only financial improvements but also this method allows to obtain environmentally friendly products and services $[15,16]$.

\section{References:}

1. N. BENAINI, "Intégration du Maroc dans les Chaînes de Valeur Mondiales: Cas du secteur de l'automobile," (May 2020).

2. K. Head, P. Martin, and T. Mayer, "Les défis du secteur automobile: compétitivité, tensions commerciales et relocalisation," Notes du conseil d'analyse économique, vol. ${ }^{\circ}{ }^{58}$, no. 4, p. 1, (2020).

3. J. P. Costa, I. S. Lopes, and J. P. Brito, "Six Sigma application for quality improvement of the pin insertion process," Procedia Manufacturing, vol. 38, pp. 1592-1599, 2019, j.promfg.2020.01.126.
4. R. G. Schroeder, K. Linderman, C. Liedtke, and A. S. Choo, "Six Sigma: Definition and underlying theory»," JOM, vol. 26, no. 4, pp. 536-554, (Jul. 2008).

5. Rahman, S. U. C. Shaju, and S. K. Sarkar, "APPLICATION OF SIX SIGMA USING DEFINE MEASURE ANALYZE IMPROVE CONTROL (DMAIC) METHODOLOGY IN GARMENT SECTOR," vol. 9, no. 3, p. 17, (2018).

6. M. Patel and D. A. Desai, "Critical review and analysis of measuring the success of Six Sigma implementation in manufacturing sector," IJQRM, vol. 35, no. 8, pp. 1519-1545, (Sep. 2018).

7. A.Trimarjoko, H. Hardi Purba, and A. Nindiani, "Management and Production Engineering, Review," (2020).

8. L. Kaouthar, "TQM and Six Sigma: A Literature Review of Similarities, Dissimilarities and Criticisms," Turk Turizm Arastirmalari Dergisi, vol. 2, no. 4, pp. 198-226, (Jan. 2021).

9. M. M. Parast, "The effect of Six Sigma projects on innovation and firm performance," IJPM, vol. 29, no. 1, pp. 45-55, (Jan. 2011) .

10. J. Wiley, "FORREST W. BREYFOGLE III," p. 1231.

11. J. de Mast and J. Lokkerbol, "An analysis of the Six Sigma DMAIC method from the perspective of problem solving," IJPE, vol. 139, no. 2, pp. 604-614, (Oct. 2012).

12. M. Ifrim, G. E. Biţan, D. Maier, and T. E. Fogoroş, "Improving the performance of organizational innovation processes by applying the Six Sigma methodology," Proceedings of the International Conference on Business Excellence, vol. 14, no. 1, pp. 1098-1108, (Jul. 2020).

13. T. Pyzdek and P. A. Keller, Six Sigma Handbook (3rd Edition). New York, USA: McGraw-Hill Professional Publishing, (2010). Accessed: (Feb. 09, 2021). [Online]. Available: http://public.ebookcentral.proquest.com/choice/pub licfullrecord.aspx $\mathrm{p}=4657706$

14. T. Stanivuk, T. Gvozdenović, J. Žanić Mikuličić, and V. Lukovac, "Application of Six Sigma Model on Efficient Use of Vehicle Fleet," Symmetry, vol. 12, no. 5, p. 857, (May 2020). 
15. A. Cherrafi, S. Elfezazi, K. Govindan, J. A. GarzaReyes, K. Benhida, and A. Mokhlis, "A framework for the integration of Green and Lean Six Sigma for superior sustainability performance," IJPR, vol. 55, no. 15, pp. 4481-4515, (Aug. 2017).
16. A. Cohen, I. Alhuraish, C. Robledo, and A. Kobi, "A statistical analysis of critical quality tools and companies' performance," JCP, vol. 255, p. 120221, (May 2020). 